Molecular Biological

Investigations of Gene

Expression Attending Fruit

Ripening: Current Status

\title{
and Future Prospects
}

David R. Dilley and Ian D. Wilson

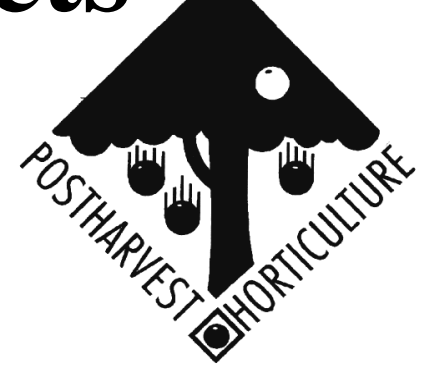

Additional index words. ACC oxidase, ACC synthase, chilling injury, enzymology, ethylene, transgenic plants 
Progress in plant molecular biology research has contributed significantly toward the understanding of the molecular basis for fruit ripening. The identification and isolation of ripening-related genes and the introduction of antisense mRNA for these genes into various plants by plant transformation has provided opportunities to control ripening of fruits and address fundamental questions of plant biology in novel ways. It has been shown that ethylene plays an essential role in fruit ripening by stimulating the expression of ripening-related genes (Grierson et al., 1985; Maunders et al., 1987), although the exact mechanism is not known. Ethylene biosynthesis and action in fruit ripening are developmentally regulated and temporally expressed; these events are modulated by numerous abiotic and biotic factors of the environment (Abeles et al., 1992). The key enzymes ofethylene biosynthesis are 1-aminocyclopropane-1-carboxylate (ACC) synthase and ACC oxidase, which catalyze the conversion of s-adenosylmethionine to ACC and ACC to ethylene, respectively. Several ethylene-responsive genes also have been isolated and sequenced. In several instances, the products encoded by these genes have been identified as specific mRNAs and/or enzymes associated with the ripening process (Brady, 1987; Grierson et al., 1986; Lay-Yee et al., 1990; Olson et al., 1991; Van Der Straeten et al., 1990). Specific ripening-related DNA sequences have been expressed in transgenic plants showing that indeed they are involved in some of the ethylene-responsive genes and some genes involved in cell wall softening (Grierson et al., 1990; Hamilton et al., 1990; Oeller et al., 1991). Fruits from antisense transgenic plants have shown (Hamilton et al., 1991) that the ethylene-forming enzyme (ACC oxidase) and ethylene are required for continuation of ripening of tomato fruits. Moreover, not all of the ripening-related processes appear to be ethylene-dependent; e.g., fruits of antisense ACC oxidase tomato plants soften. Other research with transgenic tomato plants with greatly reduced polygalacturonase (PG) has shown that $\mathrm{PG}$ is not solely responsible for softening and cell wall degradation.

Molecular biological investigations of gene expression of ripening in tomato have been particularly fruitful-literally. Transgenic plants have been produced that synthesize antisense RNA, which down-regulates the expression of several specific ripening-related enzymes, resulting in profound and specific modifications in ripening behavior. In an effort to control the rate or extent of softening during ripening, the gene encoding endo-polygalacturonase in tomato has been identified, sequenced, and down- regulated by antisense RNA technology (Smith et al., 1990). Genes encoding the enzymes ofethylene biosynthesis, ACC synthase (Nakajima et al., 1990; Olson et al., 1991; Sato et al., 1991), and ACC oxidase (Hamilton et al., 1991; McGarvey et al., 1990; Ross et al., 1992) have been isolated and sequenced. Transgenic tomato plants have been developed that produce fruits with markedly lower ethylene production capacity, which ripen slowly or are dependent upon treatment with exogenous ethylene to induce ripening (Hamilton et al., 1990; Klee et al., 1991; Oeller et al., 1991). Tomato fruits from transgenic plants in which ACC levels have been reduced or the conversion of ACC to ethylene has been reduced eventually ripen when left attached to the plants; fruits harvested when mature green show a recalcitrance to ripen fully. The developmental aspects of fruits attached to the parent plant are. still poorly understood. At equivalent stages of ripening development the ethylene concentration in fruits from the transgenic plants is often still more than adequate to initiate the cascade of events associated with normal ripening. These studies have led to greater appreciation of the complexity of regulating ethylene biosynthesis and its role in fruit ripening. Multigene families are known to be involved in the expression of ACC synthase and ACC oxidase. This is also true for the expression of these proteins in flower senescence (W.R. Woodson, personal communication).

Whereas tomato ripening has been investigated intensively in several laboratories, similar research approaches have been used in gene expression studies with avocado (McGarvey et al., 1990) and, more recently, with apple (Dong et al., 1992; Kuai et al., 1992a; Lay-Yee et al., 1990; Ross et al., 1992) and pear (Wilson et al., 1990). These studies have furthered our understanding of fruit ripening.

\section{Concepts and Protocols of Molecular Biology}

The methods and procedures involved in molecular biology investigations are mostly very explicit and exacting. When the protocols are followed precisely, the results can be definitive and generally unequivocal. Some of the concepts, terms, and commonly performed operations employed in molecular biology are now described briefly to familiarize noninitiated readers of some aspects of molecular biology as applied in fruit ripening studies. For a full review of procedures and approaches, see Berger and Kimmel (1987) and Sambrook et al. (1989). See Darnell et al. (1990) for an overview of molecular biology.

\section{6 The identification and isolation of ripening-related genes and the introduction of antisense mRNA... has provided opportunities to control ripening of fruits....}




\section{"Acc oxi- dase in apple fruit rises from nil in immature apple fruit to $\approx 5 \%$ of the soluble protein in ripe fruit in just a few days".}

The identification of specific genes related to a particular cellular process or function is generally the first step in a molecular biological investigation of fruit ripening. Sometimes the gene product is known or, if unknown, eventually can be identified. The nucleotide sequence of the DNA that comprises the gene contains the code that determines what, where, when, and how this information is transcribed, translated, and processed into gene products. DNA is the template for making various forms of RNA, which, in turn, serve as templates for making proteins. Gene libraries, a collection of DNAs representing the genome or a portion of the genome of an organism, may be prepared from fragments of the total DNA of the organism, in which case the library is called a genomic library. A gene library also may be prepared from a set of complementary DNA (cDNA) molecules copied from the mRNAs in a cell at a particular time. The cDNA library thus represents only those portions of the total DNA or the particular genes that are being expressed actively in the cell. This may be cell- or organspecific, temporal in nature, and affected by biotic and abiotic factors of the cell's environment. The nucleotide sequence of cDNA is complementary to the mRNA from which it is derived. Based on the universal genetic code where a sequence of 3 nucleotides (a codon) specifies a given amino acid, the nucleotide sequence of cDNA can be used to deduce the amino acid sequence of the resultant protein.

DNA is cleaved into fragments of differing lengths by restriction enzymes (endonucleases), which recognize specific sequences of four to six nucleotides and therefore cut the DNA molecule into fragments of welldefined length. Although discovered only 2 decades ago, nearly 1000 different restriction enzymes are now known. Restriction enzymes allow for genetic engineering, manipulation, subcloning, and production of recombinant genes. Restriction fragments may be rejoined enzymatically by DNA ligase. When DNA fragments from two genetically different DNA molecules are so joined, recombinant DNA is formed. When recombinant DNA is inserted into autonomously replicating DNA molecules called cloning vectors (plasmids or bacteriophage 1), it may be propagated in a host cell (e.g., yeast or Escherichia coli bacteria).

Specific mRNAs that determine the amino acid sequence of a particular plant enzyme or protein are translated into a protein in vivo or in vitro by a ribosomal system from the same or another organism, respectively. Transcription of mRNAs is most often the key step in gene expression, and is a highly regulated process. Specific segments of DNA containing most or all of the nucleotide se- quences to promote and transcribe a particular mRNA can be inserted into a plasmid or phage vector and incorporated into yeast or E. colias hosts to produce a particular enzyme or protein. Moreover, if the transformed host cell is provided the appropriate inducing substrate and environment, an enzyme endproduct may be produced. For example, this has been done for some restriction and cDNA cloning enzymes and artificial insulin. Another example is the expression of the gene for ACC oxidase from apple fruit into yeast as an expression vector. This was done recently in our laboratory to produce relatively large quantities of the enzyme for purification and for X-ray crystallographic studies of protein structure. We also will use the yeast expression vector for site-directed mutagenesis experiments with ACC oxidase for structure/function studies. The apple fruit ACC oxidase expressed in yeast possesses. the same enzyme reaction characteristics and stereoselectivity for $1 R, 2 S$ substrate isometry and other properties known for the enzyme (unpublished data). Moreover, the enzyme expressed in yeast contains the same epitope(s) as the native and denatured protein from apples, as based upon recognition by the antibodies we have raised against ACC oxidase.

Genes to encode the same or functionally similar proteins can be present in single or multiple copies (multigene families) within the nucleus. A multigene family expressing structurally related proteins can exist on the same or different chromosomes. This duplicity can be responsible for organ-specific and developmental or temporal regulation of gene expression. This is seen, for example, in ACC synthase (Kende, 1989). Different members may encode related, but not identical, gene products that bestow slightly different functions. Multiple copies also may support synthesis of massive amounts of a particular protein at a certain time. For example, ACC oxidase in apple fruit rises from nil in immature apple fruit to $\approx 5 \%$ of the soluble protein in ripe fruit in just a few days (Kuai et al., 1992c).

Specific nucleotide sequences upstream (5') from the initiation site, within, or downstream (3') from the transcribed region are known as promotor and enhancer elements (\&acting elements), which promote transcription in response to the binding of regulatory proteins (trans -acting factors). Some of these proteins (e.g., zinc-finger proteins) may specifically become targeted for binding to unique nucleotide sequences by first combining with low molecular weight peptides or other hormones such as abscisic acid or eth ylene-definitive evidence for this model is lacking in plants. These actions thus may affect binding and activity of RNA poly- 
merase II, which is responsible for mRNA synthesis.

If a specific gene product associated with a particular process or function can be purified, it may be used as an antigen to prepare polyclonal or monoclonal antibodies as analytical reagents. The identity of the antigen need not be known to accomplish this. If the nature of the antigen is already known as a certain protein or enzyme, so much the better. The antibody may be used as an analytical reagent to develop an ELISA enzyme-linked immunosorbant assay (ELISA).

\section{Biochemistry and Enzymol- ogy of Fruit Ripening}

Research in our laboratory (Frenkel et al., 1968) and others (Hulme et al., 1968; Richmond and Biale, 1966) beginning in the mid-1960s led to the hypothesis that ripening-related proteins were synthesized de novo as ripening proceeded and that this was essential to the ripening process. Eventually this hypothesis was proven (Brady et al., 1987). The nature of some of these ripeningrelated proteins was determined; e.g., endopolygalacturonase, NADP-malic enzyme, ACC synthase, and ACC oxidase. We began developing an ELISA to assess maturation and ripening development of apples in 1990. This led our laboratory into molecular biological investigations of ripening-related proteins; more specifically to studies on the expression of ACC oxidase, the terminal enzyme in ethylene biosynthesis. In these studies, we purified and characterized many of the properties of ACC oxidase (Kuai and Dilley, 1992; Kuai et al., 1992b) and we currently are investigating the expression and regulation of this important enzyme in pome fruit ripening (Kuai et al., 1992a). For a comprehensive review ofbiochemistry and molecular biology of fruit ripening, see Brady (1987).

\section{The Gene Expression of ACC Oxidase}

The diverse manifestations of ethylene action in plant biology (Abeles, 1973; Abeles et al., 1992; Mattoo and Suttle, 1991) occur as a consequence of ethylene's stimulating or activating gene expression, but the mechanism of ethylene action has not been resolved. In virtually all cases, de novo protein synthesis appears to be necessary for ethylene action in the chain of events initiated subsequent to the plant cell's sensing that it contains an active concentration of the gaseous hormone. It is in this context that a role for ethylene in redirecting protein synthesis in fruit ripening was first suggested more than 2 decades ago (Frenkel et al., 1968). Ethylene plays a car- dinal role in accelerating fruit ripening and plant organ senescence and in numerous morphogenic effects on plants.

ACC oxidase is expressed in a developmentally regulated manner in fruit ripening (Dong et al., 1992; Kuai et al., 1992b; Ross et al., 1992). Ethylene is known to evoke the ripening response, but the details and ethylene's role are not known with certainty. This probably involves the developmentally regulated transcription of at least one mRNA, but perhaps more are involved. The translation of these mRNAs into proteins with perhaps some post-translational modifications are also processes in which regulation ofripening may be involved. Chilling of pears induces the accumulation of ACC synthase and/or ACC, while ethylene levels in the fruit remain low (Wilson et al., 1990). Moreover, fruits from antisense-ACC synthase tomato plants, which have much reduced levels of ACC, make huge amounts of ACC oxidase, yet the ethylene production rate remains low (Grierson et al., 1990).

There are at least five genes that encode ACC synthase and three that are so far known to encode ACC oxidase. The ACC synthase genes encode proteins that share $\approx 50 \%$ similarity in amino acid sequence. There is higher similarity in amino acid sequence among the ACC oxidase-related proteins. Moreover, the cDNAs described for ACC oxidase predict one protein that shares nearly $90 \%$ similarity in the amino acid sequence for the enzyme from all of the six different plants thus far examined. One of the ACC synthaserelated genes (E8) in tomato is thought to regulate the expression of ACC synthase (Peñarrubia et al., 1992). Another ethylenerelated gene (E4) bears amino acid sequence similarity to a putative ethylene-binding protein thought to be involved in ethylene action in gene expression. It is already known that the down-regulation of the expression of the ripening-related gene ES by antisense technology effectively enhances ethylene synthesis in ripening fruits (Peñarrubia et al., 1992). The mRNAs encoded by the E8 and E4 genes are so far the earliest detectable ripeningrelated mRNAs in tomato fruit as they developmentally prepare to ripen.

In the autocatalytic (final) phase of ethylene production, a continuation of ethylene synthesis and action is necessary to sustain expression of the ripening-related enzymes (proteins) involved to continue ripening once it has begun (e.g., fruit softening, chlorophyll degradation, etc.). Cycloheximide, an inhibitor of protein synthesis, reversibly inhibits continuation of these ripening-related events (Frenkel et al., 1968) while it invariably induces the formation of ACC synthase mRNA (A. Theologis, personal communication). The
66

$T$ here are at least five genes that encode ACC synthase and three that are so far known to encode $A C C$ oxidase." 
66

...cooperation

between growers, physiologists,

biochemists, molecular

biologists, and

plant breeders/

geneticists has

been, and still is, extemely

important." inability of cycloheximide to block transcription of ACC synthase suggests that transacting proteins are present before the fruit shows a visible symptom of the onset of ripening. These may act on the cis- elements of the promoter sequence for ACC synthase. These proteins may become activated by an elicitor yet to be identified. A model for this cycloheximide-insensitive transcriptional activation was recently described by Schindler et al. (1992) for interon-dependent tyrosine phosphorylation of a latent cytoplasmic transcription factor. This was also found by David and Larner (1992). This mechanism of transcriptional activation was found to be independent of second messengers in the cell such as $\mathrm{Ca}^{2+}-$ calmodulin (Schindler et al., 1992). Similar studies with known elicitors of transcriptionalactivation in plants should be given high priority in future research. Among the elicitors known to activate transcription are: the pathogenesis-related elicitors (Spanu et al., 1992); the wound-induced systemin (McGurl et al., 1992); and several of the already known plant hormones (abscisic acid, auxin, gibberellin, and salicylic acid). Inhibition of ethylene action by $\mathrm{Ag}^{+}$and other ethyleneaction inhibitors prevents initiation of ripening and also prevents continuation of these processes once begun (Saltveit et al., 1978).

\section{Future Prospects for Mo- lecular Biological Studies of Gene Expression of Ripening}

Some of the promises of molecular biology heralded 2 decades ago are now coming to fruition in animal and plant biology. $\mathrm{Nu}-$ merous examples can be cited where molecular biology research has yielded definitive and fundamental knowledge of enzyme reaction mechanism, protein structure, and site and action ofhormones. Specific genes have been genetically engineered. Genes from one organism have been incorporated into the DNA of another. Transgenic plants have been developed with a wide range of attributes of potential commercial importance to agriculture, such as resistance to or tolerance to insects, diseases, and herbicides. Transgenic plants also have been developed employing antisense RNA, in which their ability to produce a normal complement of a specific enzyme has been reduced. Yeasts, bacteria, and some plants have been transformed to become "factories" to produce specific enzymes and products. Calgene, Inc., a California-based biotech company, was given approval in the United States in May 1992 to commercialize a genetically engineered tomato with delayed cell wall softening characteristics.

It has been more than 30 years since
Steward (1958) first demonstrated the totipotency of plant cells and proposed that the expression of plant genes is temporally and developmentally regulated. Since then, the molecular biology of plant cells has become a complicated scientific research area. Over the past decade, numerous DNA sequences associated with the temporal, developmental, and organ-specific regulation of particular subsets of genes have been isolated. As such, the techniques are now available whereby specific phenotypic traits can be characterized and altered by genetic engineering. However, of the multitude of physiological processes that lend themselves to this manipulation, relatively few have been examined in depth. At this point, research is conducted mainly on genes with high levels of expression. There are, of course, exceptions, with fruit ripening being the most obvious. If we examine why this particular area of research has been so successful it becomes obvious that the cooperation between growers, physiologists, biochemists, molecular biologists, and plant breeders/geneticists has been, and still is, extremely important. In light of the present economic constraints, the movement towards commercially oriented science is likely to continue, if not accelerate. The resultant reality is that, in order to survive, individual researchers in all the fields must cooperatively coordinate their experience, expertise, and ambitions. Almost traditionally, the different research fields have become exclusive. Researchers are trained in their specific fields, and for numerous reasons find it difficult to communicate outside of their specialties. One reason for this is that scientists tend to specialize in limited research areas to become successful. Such exclusivity is no longer the route by which progress can be achieved. Plant science has moved to the point that it is now possible to determine the molecular processes underlying the gross morphological and physiological effects that may result when plants are grown under specific environmental conditions. That is not to say that physiologists have become obsolete. They now have the golden opportunity to explore the reasons behind the phenomena that they observe and can more effectively manipulate the traits of interest. Indeed, cooperative ventures initiated by fruit growers, physiologists, and industries may lead to exciting new discoveries that not only benefit science as a whole, but may further the careers and opportunities of all the individuals involved.

Many exciting, worthwhile, and potentially feasible objectives may be envisioned where molecular biology may be employed to modify or improve diverse pre- and postharvest attributes of fruits. These may relate to: control ofpreharvest drop of fruits; improved quality in terms of size, color, flavor and 
nutritive value; control ofripening in its many manifestations; control of physiological disorders such as apple scald and other chillingrelated disorders; and improved disease resistance.

Studies of the influence of chilling or low temperature storage of fruits is a good example of how molecular biology research may provide improved postharvest characteristics of some fruits. The pre- and postharvest handling of pome fruits is linked integrally with exposure to and the use ofreduced temperatures. While fruit harvested in the correct physiological condition can be stored for extensive periods at reduced temperatures, there are still problems. A sudden preharvest decline in the environmental temperature can result in premature fruit drop, a particular problem of 'Bartlett' pears (Hansen, 1961; Ing, 1968; Wang et al., 1971) that limits the northern or southern latitude or elevation at which these fruits may be grown successfully. Furthermore, fruit exposed to preharvest chilling temperatures often store poorly under refrigeration, with the resultant loss of marketable quality (Porritt, 1964). Much work has demonstrated that the effect of periods ofchilling temperature on pome fruits is the induction ofripening and the associated synthesis of ethylene (Blankenship and Richardson, 1985; Jobling et al., 1991; Knee, 1987; Sfakiotakis and Dilley, 1974; Wang et al., 1971). It is accepted generally that many pear and some apple cultivars actually require a period of chilling exposure in order to ripen subsequent to returning them to ambient temperatures. This suggests the existence of a genetically controlled system of cold-regulated gene expression for the ripening of some pome fruits. The identification of coldregulated DNA sequences from pears and apples would allow significant modification ofexisting cultivars. For example, the cold induction of ethylene synthesis by mature fruit could be down-regulated in an organ-specific fashion by antisense technology. This would suppress the normal cold-induction of fruit ripening, alleviate the problem of premature fruit drop, facilitate the cold storage of fruit and allow the manipulation of fruit ripening by the application of exogenous ethylene.

Down-regulating ethylene production of selected cultivars of apples and pears, thereby making ripening dependent on exogenous ethylene treatment, could also be an important achievement. This could make their handling, storage, and ripening regimens much like that employed currently for 'Valery' bananas. Postharvest preservation technologies could be employed that are much less sophisticated and energy-intensive.

Many of the objectives of molecular biological investigations have important im- plications related to contemporary concerns, such as reducing the dependence on the use of pesticide chemicals and energy consumption in the production and postharvest conservation of fruits. Significant progress towards these objectives will depend on collaboration between horticulturists, geneticists, plant physiologists, and molecular biologists. Important problems, constraints, and opportunities must be identified; resources must be assessed; costs and benefits appraised; environmental and food safety risks assessed; appropriate research approaches must be outlined, experimentation conducted, and results assessed. Future achievement of the researchable and worthwhile objectives will be fostered by a team approach. Implementation of the cost-effective results of these endeavors will depend on viable industries to employ them; other industries to market the technologies; and wise and prescient persons in governmental and regulatory agencies to assure safety of the foods and to protect the environment. Questions about the safety of the foods and feeds produced from transgenic plants have not been fully resolved. Moreover, the genetic interactions of transgenic plants with the genomes of the native species that have evolved over eons of time remain to be determined in the future.

\section{Literature Cited}

Abeles, F. W. 1973. Ethylene in plant biology. Academic, New York.

Abeles, F. W., P. W. Morgan, and M.E. Saltveit. 1992. Ethylene in plant biology, 2nd ed. Academic, New York.

Berger, S.L. and A.R. Kimmel (eds.). 1987. Crude $\mathrm{Z}$ molecular cloning techniques. Methods in enzymology. vol. 152. Academic, New York.

Blankenship, S.M. and D.G. Richardson. 1985. Development of ethylene biosynthesis and ethylene induced ripening in D'Anjou pears during the cold requirement for ripening. J. Amer. Soc. Hort. Sci. 110:520-523.

Brady, C.J 1987 Fruit ripening. Annu. Rev. Plant Physiol. 38:155-178.

Darnell, J., H. Lodish, and D. Baltimore. 1990. Molecular cell biology, 2nd ed. Freeman, New York.

David, M. and A.C. Larner. 1992. Activation of transcription factors by interferon-alpha in a cellfree system. Science 257:813-815.

Dong, J. G., D. Olson, A. Silverstone, and S.F. Yang. 1992. Sequence of a cDNA coding for a 1 -aminocyclopropane-1 -carboxylate oxidase homolog from apple fruit. Plant Physiol. 98:1530-1531.

Frenkel, C., I. Klein, and D.R. Dilley. 1968. Protein synthesis in relation to the ripening of pome fruit. Plant Physiol. 43:1146-1153.

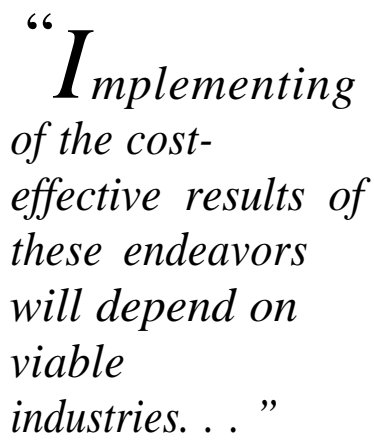

${ }^{66}$ of the costeffective results of these endeavors will depend on viable industries. . ." 
Grierson, D., A. Slater, M. Maunders, P. Crookes, G.A. Tucker, W. Schuch, and K. Edwards. 1985. Regulation ofexpression of tomato ripening genes. Theinvolvement of ethylene, p. 147-161. In: J.A. Roberts and G.A. Tucker (eds.). Ethylene and plant development. Butterworths, London.

Grierson, D., G.A. Tucker, J. Keen, J. Ray, C.R. Bird, and W. Schuch. 1986. Sequencing and identification of a cDNA clone for tomato polygalacturonase. Nucleic Acid Res. 14:8595-8603.

Grierson, D., C.J.S. Smith, C.F. Watson, P.C. Morris, J.E. Gray, K. Davies, S.J. Picton, G.A. Tucker, G.B. Seymour, W. Schuch, C. R. Bird, and J. Ray. 1990. Regulation of gene expression in transgenic tomato plants by antisense RNA and ripening specific promoters, p. 115-125. In: G.W. Lycett and D. Grierson (eds.). Genetic engineering of crop plants. Butterworths, London.

Hamilton, A.J., M. Bouzayen, and D. Grierson, 1991. Identification of a tomato gene for the ethylene-forming enzyme by expression in yeast. Proc. Natl. Acad. Sci. USA 88:7434-7437.

Hamilton, A.J., G.W. Lycett, and D. Grierson. 1990. Antisense gene that inhibits synthesis of the hormone ethylene in transgenic plants. Nature (London) 346:284-287.

Hansen, E. 1961. Climate in relation to postharvest physiological disorders of apples and pears. Annu. Rpt. Ore. State Hort. Soc. 53:54-58.

Hulme, A.L., M.J.C. Rhodes, T. Galliard, and L.S.C. Wooltorton. 1968. Metabolic changes in excised fruit tissue. IV. Changes occurring in disks of apple peel during the development of the respiration climacteric. Plant Physiol. 43:1154-1161.

Ing, G. 1968. Premature pear ripening. Proc. Wash. State Hort. Soc. p. 196-199.

Jobling, J., W.B. McGlasson, and D.R. Dilley. 1991. Induction of ethylene synthesizing competency in Granny Smith apples by exposure to low temperature in air. Postharvest Biol. \& Technol. 1:111-118.

Kende, H. 1989. Enzymes of ethylene biosynthesis. Plant Physiol. 91:1-4.

Klee, H.J., M.B. Hayford, K.A. Kretzmer, G.F. Barry, and G.M. Kishore. 1991. Control of ethylene synthesis by expression of a bacterial enzyme in transgenic tomato plants. The Plant Cell 3: 11871193.

Knee, M. 1987. Development of ethylene biosynthesis in pear fruit at $-1{ }^{\circ} \mathrm{C}$. J. Expt. Bot. 38:17241730 .

Kuai, J. and D.R. Dilley. 1992. Extraction, partial purification and characterization of 1-aminocyclopropane- 1 -carboxylic acid oxidase from apple fruit. Postharvest Biol. \& Technol. 1:203-211.

Kuai, J., D. Dixon-Holland, Y. Zhu, and D.R. Dilley. 1992a. Expression of 1-aminocyclopropane1-carboxylate oxidase during apple (Malus domestica Borkh.) fruit ripening. Plant Physiol. (In press.)

Kuai, J., Y. Zhu, Y. Pekker, and D.R. Dilley. 1992b. Purification and characterization of 1-aminocy- clopropane-1-carboxylic acid oxidase from apple fruit. Plant Physiol. (In press.)

Lay-Tee, M., D. DellaPenna, and G.S. Ross. 1990. Changes in mRNA and protein during ripening in apple fruit (Malus domestica Borkh. cv. Golden Delicious). Plant Physiol. 94:850-853.

Mattoo, A.K. and J.C. Suttle. 1991. The plant hormone ethylene. CRC Press, Boca Raton, Fla.

Maunders, M.J., M.J. Holdsworth, A. Slater, J.E. Knapp, C.R. Bird, W. Schuch, and D. Grierson. 1987. Ethylene stimulates the accumulation of ripening related mRNAs in tomatoes. Plant Cell \&Environ. 10:117-184.

McGarvey, D.J., H. Yu, and R.E. Christoffersen. 1990. Nucleotide sequence of a ripening-related cDNA clone from avocado fruit. Plant Mol. Biol. 15:165-167.

McGurl, B., G. Pearce, M. Orozco-Cardenas, and C.A. Ryan. 1992. Structure, expression and antisense inhibition of the systemin precursor gene. Science 255:1570-1573.

Nakajima, N., H. Mori, K. Yamazaki, and H. Imaseki. 1990. Molecular cloning and sequence of a complementary DNA encoding 1-aminocyclopropane- 1 -carboxylate synthase induced by tissue wounding. Plant Cell Physiol. 31:1021-1029.

Oeller, P. W., L. Min-Wong, L.P. Taylor, D.A. Pike, and A. Theologis. 1991. Reversible inhibition of tomato fruit senescence by antisense RNA. Science 254:437-439.

Olson, D. C., J.A. White, L. Edelman, R.N. Harkins, and H. Kende. 1991. Differential expression of two genes for 1-aminocyclopropane- 1 -carboxylate synthase in tomato fruit. Proc. Natl. Acad. Sci. USA 87:7930-7934.

Peñarrubia, L., M. Aguilar, L. Margossian, and R.L. Fischer. 1992. An antisense gene stimulates ethylene hormone production during tomato fruit ripening. The Plant Cell 4:681-687.

Porritt, S. W. 1964. The effect of temperature on postharvest physiology and storage life of pears. Can. J. Plant Sc. 44:568-579.

Richmond, H. and J. Biale. 1966. Protein and nucleic acid metabolism in fruits. I. Studies of amino acid incorporation during the climacteric rise of avocado. Plant Physiol. 41:1247-1253.

Ross, G.S., M.L. Knighton, and M. Lay-Tee. 1992. An ethylene-related cDNA from ripening apples. Plant Mol. Biol. 19:231-238.

Saltveit, M.E., K.J. Bradford, and D.R. Dilley. 1978. Silver ions inhibit ethylene synthesis and action in ripening fruits. J. Amer. Soc. Hort. Sci. 103:472-475.

Sambrook, J., E.F. Fritsch, and T. Maniatis (eds.). 1989. Molecular Cloning. A Laboratory Manual. 2nd ed. Cold Spring Harbor Laboratory, Cold Spring Harbor, New York.

Sato, T., P. W. Oeller, and A. Theologis. 1991. The 1-aminocyclopropane-1-carboxylate synthase of Cucurbita. Purification, properties, expression in 
Escherichia coli, and primary structure determination by DNA sequence analysis. J. Biol. Chem. 266:3752-3759.

Schindler, C., K. Shuai, U.R. Prezioso, and J.E. Darnell, Jr. 1992. Interferon-dependent tyrosine phosphorylation of a latent cytoplasmic transcription factor. Science 257:809-813.

Sfakiotakis, E.M. and D.R. Dilley. 1974. Induction of ethylene production in Bosc pears by postharvest cold stress. Hort. Sci. 9:336-338.

Smith, C.J.S., C.F. Watson, P.C. Morris, C.R. Bird, G.B. Seymour, J.E. Gray, C. Arnold, G.A. Tucker, W. Schuch, S.F. Harding and D. Grierson. 1990. Inheritance and effects on ripening of antisense polygalacturonase genes in transgenic tomatoes. Plant Mol. Biol. 14:369-379.

Spanu, P, G. Felix, D. Grosskopf; D. Reinhardt, and T. Boller. 1992. Induction of ethylene biosynthesis by elicitors. Cellular and molecular aspects of the plant hormone ethylene. Kluwer, Dordrecht, The Netherlands.
Steward, F.C., M.O. Mapes, and K. Mears. 1958. Growth and organized development of cultured cells. III. Interpretations of the growth from free cell to carrot plant. Amer. J. Bot. 45:705-713.

Van Der Straeten, D., L. Van Wiemeersch, H.M. Goodman, and M. Van Montagu. 1990. Cloning and sequence of two different cDNAs encoding 1-aminocyclopropane-1-carboxylate synthase in tomato. Proc. Natl. Acad. Sci. USA 87:48594863.

Wang, C.Y., W.M. Mellenthin, and E. Hansen. 1971. Effect of temperature on development of premature ripening in Bartlett pears. J. Amer. Soc. Hort. Sci. 96:122-125.

Wilson, I.D., G.A. Tucker, M. Knee, and D. Grierson. 1990. Changes in mRNA during low temperature storage and ripening of pears. Phytochemistry 29:2407-2409. 